\title{
"Computer Engineering Online" using the Novel eLearning 3.0 Platform Wiki-Learnia
}

\author{
http://dx.doi.org/10.3991/ijac.v6i1.2479 \\ I. Waßmann and D. Tavangarian \\ University of Rostock, Rostock, Germany
}

\begin{abstract}
To counter the growing lack of experts in the IT sector, and to give at the same time a possibility for lifelong learning, a consortium of north German universities has initiated the project "Computer Engineering Online“. The goal is to develop an online study program for computer engineering in 2013. Referred to the blended learning strategy, the bigger part of the Bachelor's program is offered by an online portal. Here, the open source platform ILIAS is used which is optimized for the use in academic environments. Due to other qualifications of the target group, the Master's program is realized by a further education mechanism embedded in a completely novel eLearning 3.0 platform called "Wiki-Learnia" which combines formal and informal learning.
\end{abstract}

Index Terms - online studying, lifelong learning, eLearning 3.0, eLearning-Hub.

\section{INTRODUCTION}

The computer engineering has changed the world dramatically within a few years by the growing penetration of complex embedded systems in all areas of life. In industry for example, production machines are fully controlled by computational systems. Almost every new car includes sensors, actuators, and a corresponding communication network to support the driver with various assistance systems, for instance air bags, autobrakes, lane departure warning systems, and automatic parking. Other important applications of computer engineering are medicine, building automation, aeronautics and astronautics, mobile telephony, and many more.

Due to the continuously technological innovations and developments and their ever-widening penetration in everyday's life, extra-occupational studying as well as lifelong learning is more needed than ever before. People from the technological sector periodically need to expand their knowledge about technologies and procedures of the current state of the art. This implies a lifelong learning in the form of further education.

Furthermore there's a growing lack of experts as employees in the German IT sector. In general 210.000 STEM-skilled workers (science, technology, engineering, mathematics) are needed in Germany in year 2012 [1]. Especially in the IT sector there're around 43.000 job vacancies for IT experts in the German economy. The diagram in Figure 1 shows that this number is increasing rapidly each year. With other words there's a negative trend since several years which has to be stopped.

For this reasons, a consortium of five north German universities develops the eLearning solution "Technische Informatik Online” (TIO; English: "Computer Engineering Online”) [3], which will start in year 2013.

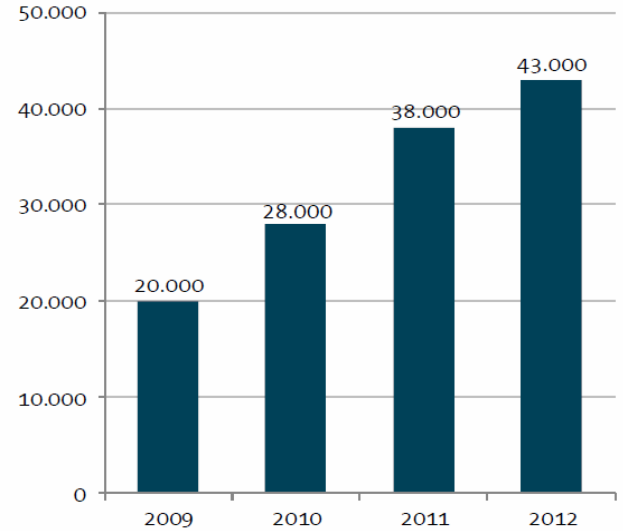

Figure 1. Job vacancies in German IT sector (2012) [2]

This allows both full-time and part-time studies, for example for people who have to work on the side, or are in a fostering situation.

As a result, the project reflects the fact that studying in today's information society is subject to revolutionary changing processes [4]. This applies to the external conditions, such as media, learning places and times, and the internal conditions, such as motivation, learning speed and performance monitoring of the learners. TIO is a learner-centered approach where the user decides when and where he is learning. The course contents are available on the Internet from any device, at any place and at any time.

There's one study program for a Bachelor's (Bachelor of Science, B.Sc.) and one for a Master' degree (Master of Science, M.Sc.), which is the basis for subsequent doctoral studies (Ph.D.).

The former one is presented in the second section. Especially the used system architecture based on the open source platform ILIAS is described in detail. The Master's program as a further education concept is introduced in the following section III. Due to other circumstances related to the prior knowledge and learning behavior of the target group, here a completely novel eLearning platform called "Wiki-Learnia" is used, which is depicted in the subsequent section. Finally all contents of this contribution are summarized and information about release dates is given in the outlook.

\section{TIO - BACHELOR}

In Figure 2 the module catalogue of the Bachelor's program is showed, which consists of six semesters. The first four semesters constitute the basic studies which communicate basic knowledge in the fields of computer science and electrical engineering. In the last two semesters the 
PAPER

“COMPUTER ENGINEERING ONLINE” USING THE NOVEL ELEARNING 3.0 PLATFORM WIKI-LEARNIA

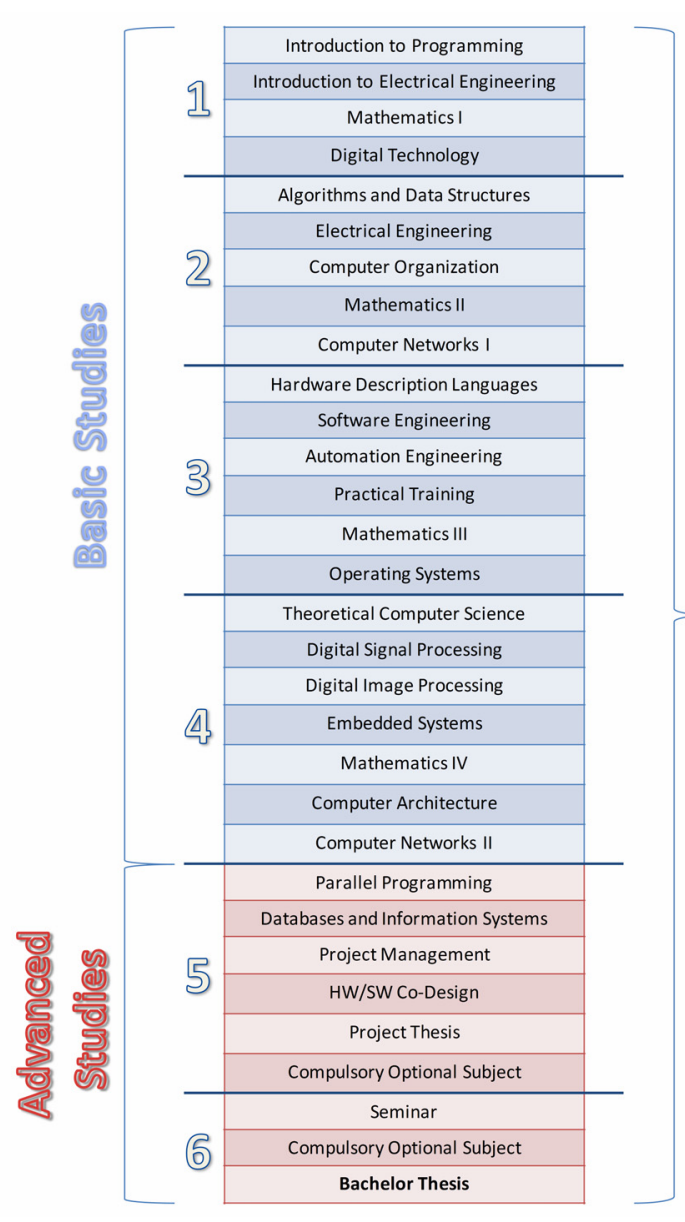

Figure 2. Curriculum of the Bachelor's program

students take advanced courses, and can select compulsory optional subjects they're interested in. In the end, they have to write a Bachelor thesis to demonstrate that they can work independently and scientifically. At a conclusion, they will get the Bachelor of Science degree (B.Sc.).

\section{A. Overview of the System Architecture}

Figure 3 gives an overview of the architecture of the whole process for TIO’s Bachelor study program (B.Sc). After a brief workflow description, the individual components are presented more in detail in the following sections.

It's a single source publishing principle which means that all input data is converted into an intermediate format, which is the basis for all output transformations. Otherwise, changes to the output content are directly written back to the input data via the intermediate format. This work is performed by the "Editing-Server", which is the core element in this architecture. It gets input by the authors who upload learning content in different file formats to the server by means of a webfrontend. Then this data will be converted automatically in an XMLformat, which will be saved in a database. Using this data, now the output files can be generated and are delivered by the "Live-Server" to the learners. Additionally, a "Streaming-Server" provides multimedia data which is integrated in the outputs. All data will be automatically adapted for different devices (mLearning).

\section{B. Webfrontend}

As an interface for the authors and administrators there is a webfrontend which is used to interact with the overall system.

Authors are scholars, mostly professors or doctors who create the teaching content in the form of manuscripts enriched with multimedia data. They can use their usual word processing programs and then upload it to the server. For this purpose, there are templates for OpenOffice Writer and Microsoft Word, as well as for LaTeX. These include a set of formatting rules which the authors have in mind when creating their content. Besides that, they have to ensure self-dependently an adequate level of didactics, semantic quality, as well as spelling and grammar.

The structure of an eLearning module for the Bachelor's program is well defined in TIO. It includes a description of the eLearning module composed of a brief summary of the learning contents, a brief presentation of the author(s) and the relation to the curriculum. The organization part gives information about the whole process of the eLearning module, when the class lectures take place, when there will be tests et cetera. The necessary conditions for participation, for example prior knowledge, successfully completed tests, and previously attended courses, are given in the qualification. The learning content is included in one or more learning objects which have the following structure:

- Overview: It shows the main information about the learning object, like the learning goal, the index of contents, the expected expenditure of time and so on.

- Learning Content: This is the hierarchically arranged thematic content of the course which includes texts and multimedia data.

- Exercises and Tests: Real-world tasks support the understanding of the curriculum and serve as a control of the own learning process.

- Miscellaneous: Required software tools for solving the exercises, recommended and further readings, a glossary and other things can be found here.

All files can be uploaded individually or as a zipped format to the server.

Furthermore, administrators have access to the webfrontend to manage the whole system. They can create, edit and delete users, monitor the databases and make some system-relevant settings. All authentications are realized by a user database, which is part of the EditingServer.

\section{Editing-Server}

The Editing-Server is the core element in the entire architecture which includes all converters, as well as the main databases. After authors uploaded learning content, it will be transformed to an XML-format called "XML4TIO" by means of developed converters. XML4TIO is a light version of the Multidimensional LearningObjects and Modular Lectures Markup Language $\left(<M L^{3}>\right)$ [5]. The flexibility of this XML dialect allows the encoding of all the educational content of manuscripts: texts with all prevalent formats, captions, indexes, as well as embedded elements including labels like pictures, tables, formulas and source codes of certain programming languages.s 


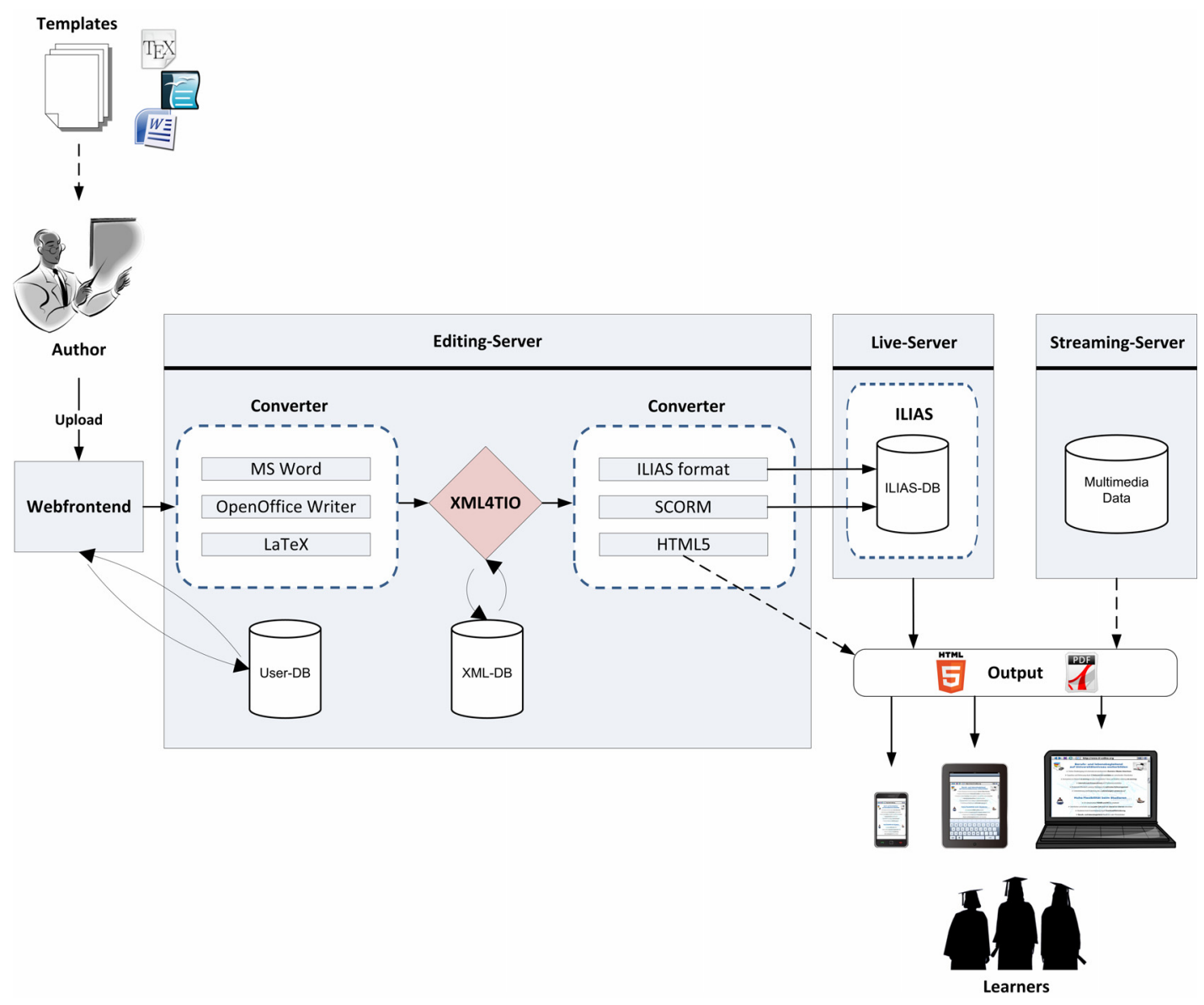

Figure 3. System architecture of the Bachelor's program

All XML-files are saved in a database, which includes a versioning mechanism so that authors can publish certain versions of their scripts. Furthermore, there is a connection to a backup server to avoid data loss caused by technical errors.

According to the single-source publishing approach, now any output formats can be generated. If this data will be modified, changes can be directly written back to the XML structure [6]. For the transformations, appropriate converters were implemented. There is one converter to get Hypertext Markup Language 5 (HTML5) websites which can be directly published to the user. The necessary representational adaptations for different display resolutions of available devices, such as personal computers (PC), notebooks, tablet PCs, or smartphones, are realized by using Cascading Style Sheets (CSS). With the native support of audio and video content, as well as the integration of dynamic 2D and 3D graphics, HTML5 is well suited for displaying learning content including multimedia data.

Another converter is used to generate a Sharable Content Object Reference Model (SCORM) - Container. SCORM was developed by the Advanced Distributed Learning (ADL) Initiative to provide an eLearning standard for sharing learning content between several learning management systems (LMS).

\section{Live-Server}

One of these LMS is the open source eLearning platform ILIAS [7] which is the basis of the Live-Server. On the one hand, the learning content based on XML4TIO can be transformed to an ILIAS-compatible format or SCORM, and then can be imported to ILIAS. On the other hand, there is a possibility to create content directly in ILIAS, which can be later exported to SCORM.

There are several roles in TIO supported by ILIAS that are presented in the following.

A team of administrators, assessors, and developers is responsible for the technical support of the platform. Developers implement new features, and optimize all system processes. The administrators activate the new or existing plug-ins, add users, manage system settings, change skins, and review statistics about accesses and learning progresses. Based on user's feedback, assessors evaluate the features and system processes, and share the results with the developers.

Another group of roles, consisting of authors, tutors, and teachers, are responsible to create, and to communicate learning content, as well as to support the students. Tutors, for example students from higher semesters, or other academics, supervise students, answer questions, check exercises and tests, and can also act as authors by creating learning content. Teachers are responsible for one or more eLearning modules, create learning material, exercises and tests, and manage the whole process. This includes the dates of class lectures, exams, consultations et cetera. Authors can be both tutors and teachers, or other external writers who provide content for TIO.

Users of these roles can create courses in ILIAS, and add learning contents, as well as many web 2.0 features. There are communication services, like forums, chat rooms, and wikis, which promote the cooperative work of 
students, and provide a feedback option for both students and tutors. The latter can add web links, web feeds and media casts to complete their manuscripts with multimedia data. For interaction with the learners, and to check the learning progress, there is the possibility to insert surveys, exercises, and tests. This offers the opportunity to impose admission restrictions for examinations. For this purpose, there are a number of test types, like cloze questions, error texts, essay questions, ordering questions, numeric questions, multiple choice questions, hot spot questions, java applet questions and many more.

The last group of roles includes the learners which can be pupils and students for academic education, or employees of a company for further qualification.

In ILIAS, learners can join the offered courses, and read or download the learning material. They can create notices, chat or e-mail with other students and tutors, manage bookmarks, edit the own profile site, and can use a calendar for coordination. In addition, learners have a dedicated work area called "My Workspace" where they can collect files, web links, personal blogs, and certificates they achieved. All these things can be integrated in addition to the profile information in an ePortfolio. There are three different scenarios for ePortfolios [8], which are supported by ILIAS:

- Those for developmental purposes: It is used to document learning, to reflect on it, and to correct it if necessary. The users can collect certain artifacts (learning successes and work samples), and combine them to show their learning goals.

- Those for presentation purposes: This is used for the presentation of acquired skills for third parties. The own competences can be supplemented with artifacts, and can be added to a curriculum vitae.

- Those for assessment purposes: Created ePortfolios can be submitted as results of exercises or tests. The tutor provides a framework (period/deadline, scope, group or individual), and at the end he will give a feedback, for example in the form of a rating.

Beyond these existing features of ILIAS, the working team of TIO develops a few new services for the users. There will be an extended feedback system, so learners can advise the authors of good and bad aspects about their manuscripts. An advanced search system to find teaching materials will be implemented. Furthermore, the setting of bookmarks within the manuscripts, as well as a status bar to indicate the learning progress will assist student's learning. To provide practical experiences, simulations and virtual labs are being developed. For example, a program to verify Very High Speed Integrated Circuit Hardware Description Language (VHDL) syntax is in progress.

Another research area concerns the work on new modern eLearning mechanisms, such as a method for live blended learning. This term is referred to the production of a media-based hybrid or multidimensional learning space in order to exploit the emergent effects of a cooperative knowledge management for collaborative learning contexts as a kind of face-to-face courses. From a practical point of view it is a live face-to-face eLecture which consists of audio or video streams, associated synchronized presentation slides, and the possibility to communicate with tutors and other students for collaboration and cooperation in real-time. This paves the way towards a pervasive university [9].

\section{TIO - MASTER}

Furthermore, the consortium decided to offer a Master's program, too. It only consists of three semesters valued at 90 ECTS, including two semesters with lectures and one semester for the Master thesis. Students will be free to choose their eLearning modules. In addition to simple manuscripts (not necessarily full text), the learner is supported by recorded video lectures. For example at University of Rostock, there are more than 50 courses like Continuous and Hybrid Systems Modeling and Simulation, Human Computer Interaction, Middleware, NetworkBased Applications and Services, Scalable Computing, Multimedia Information Systems and many more. This is the basis for a subsequent doctoral program (Ph.D.) with a volume of six until eight semesters.

In contrast to the Bachelor's program, the TIO Master isn't designed as a classical blended learning approach. Master students are more experienced because they have already obtained a first higher education degree, and most of them have practical training by working in industry. In contrast, young graduates from secondary school need a better support embedded in a more didactical framework. For this reason the TIO Bachelor's program is based on full text manuscripts delivered by a well-known platform which is especially designed for those purposes. ILIAS is used at many schools, universities, and other educational institutions, so it's optimized for teaching approaches based on direct instruction or lecturing accompanied by real-world seminars. The Master's program of TIO is designed as an extra-occupational further education approach. For this purpose, an entirely novel eLearning 3.0 portal called "Wiki-Learnia" is used, which is a further education approach by design. A social network environment to raise cooperation between learners, certain recommendation mechanisms to support the user while searching for relevant further education topics, and many other concepts presented in the following sections are properties of this new eLearning platform.

Before this description, in the following two different target groups of the Master's program are showed. The first group includes people who have just completed their Bachelor studies and wish to connect directly to the Master's program. The amount of German Bachelor graduates of this category in year 2010 [10] are listed in the following:

- Computer Engineering: 696;

- Computer Science: 3.264;

- Computer \& Communication Technologies: 278;

- Physics: 1.392;

- Technical Mathematics: 106;

- Business Informatics: 2.998.

While graduates of the first two study programs with a total of nearly 4.000 potential students are very well suited for a Master's program in computer engineering, the latter ones are career changers which may require additional semesters to make up for some of the basics they missed in their specializations. Overall there's a wide target group with a lot more than 4.000 potential Master students. Furthermore, this number is still rising every year as can be seen in [10]. 
The second target group consists of active working people with further qualification intentions in an extraoccupational way. The amount of those people is difficult to estimate, but it should be a constantly growing group due to the rapidly increasing demand of further education (described in section I).

\section{WIKI-LEARNIA - AN ELEARNING 3.0 PORTAL}

Besides to the presented academic distribution channel with the goal to gain a Bachelor's degree by a university examination procedure, there's another one embedded in a social environment to achieve certificates just for further qualification or also to gain a Master's degree. Here, not ILIAS as platform is used, but an entirely novel one called "Wiki-Learnia" which will be actually developed by the University of Rostock. TIO will be one of the first contents when starting in pilot phase at the beginning of 2013. It's an eLearning $\mathbf{3 . 0}$ portal which combines social learning aspects with recommendation mechanisms and mLearning technologies.

To understand the term “eLearning 3.0”, it's necessary to know the meaning of Web 3.0, which is not yet completely defined. Based on [11] the following sections give an overview of the evolution of Web 1.0 up to Web 3.0 and corresponding eLearning concepts integrated into Wiki-Learnia.

\section{A. Web/eLearning 1.0 Features}

At First, there was the Web 1.0 which gave an easy access to information across the world. It's the so-called "read-only Web" [12] where users only can easily consume, but not produce content. In analogy the term "eLearning 1.0" is described as an easy access to learning content. The first LMSs just offered possibilities to manage learning material by dividing it into learning objects (modules, courses, and lectures) enriched with simple quizzes, tests and discussions [11].

Although Wiki-Learnia is based on the "Wikipedia thought" that every user can create and edit content, it's also possible to include special content for certification. This cannot be modified by the community, but can be annotated for own notices, as well as commented to give advises for revisions. As Wiki-Learnia is designed for further education, certain institutions like universities or schools can add such "read-only" material. In WikiLearnia learning content is based on a special didactic structure visualized in Figure 4.

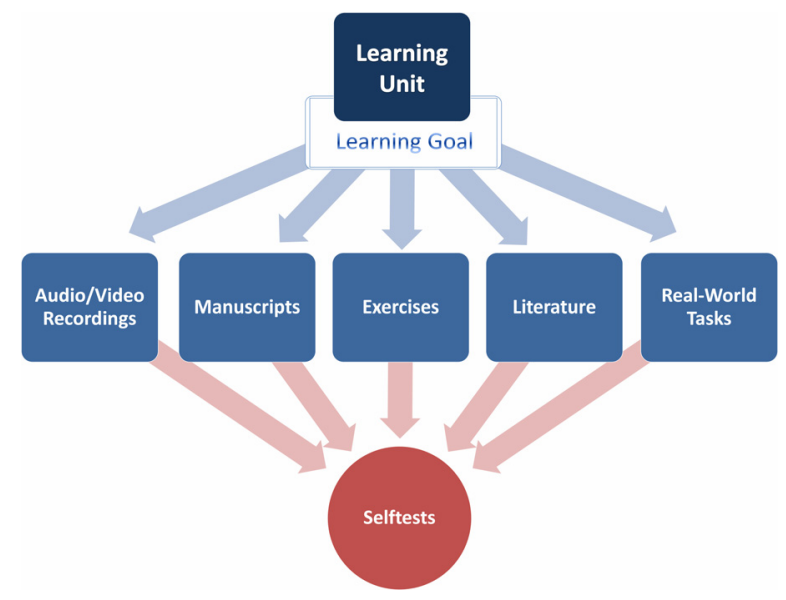

Figure 4. Learning Units in Wiki-Learnia
The basis is a learning unit, described by a learning goal, which is equivalent to the extent of two classroom teaching lessons (ca. 90 min.). Depending on special content-related and didactical issues, a learning unit may involve several different elements:

- audio and video recordings, i.e. of lectures, enriched with presentation slides, and navigation as well as search features;

- manuscripts (full text, presentation slides etc.) in printable and different digital versions, such as MediaWiki, HTML5, Word, or PDF format;

- some content-related exercises which should be processed, and documented by the recipients;

- literature references from real-world as well as digital libraries (i.e. links to Wikipedia, Google Books etc.) for independent, more detailed studies;

- real-world tasks in form of laboratory training by means of simulations, remote labs, as well as supervised face-to-face courses.

Accompanied by these learning elements, there're selftests in form of simple quizzes like multiple choice tests (based on existing MediaWiki extensions) etc. to control the own learning progress. If unsuccessful, the procedure can iteratively be repeated with new learning elements. After the completion of a learning unit it can be either continued directly with the next one, or a certification can be done.

A combination of several of those learning units with related topics can form a learning module with corresponding ECTS points. In turn, several modules can be picked together to reach the extent for a whole semester at a university or a vocational college. The material for several semesters supplemented with practical work under institutional supervision can be orchestrated an entire study course. Modules which are used for certification have to be assessed by assessors in content, scope, structure, didactics etc., and the curriculum must be accredited.

An important cornerstone of the approach is the structuring of the offered content, so there's the possibility for taking individual modules as well as thematic combinations of modules up to the combination of learning content to complete study courses. All content in Wiki-Learnia is free to use, so everybody can use it for at least informal learning processes. If a user wishes to achieve a certificate, he has to do an explicit registration, and pay money for needed support which may occur in a blended learning method (i.e. with face-to-face presence seminars), as well as the final examinations. On this way, Wiki-Learnia combines innovatively formal and informal learning.

\section{B. Web/eLearning 2.0 Features}

The second eLearning phase was initiated by Web 2.0 which is well-known as "read-write web" [12]. New web technologies like blogs, wikis, and social networks allow people to create own content, even collaboratively with other users. They can discuss or solve cooperatively certain problems, and compare opinions [11]. Furthermore, eLearning 2.0 LMSs are characterized by learning content enriched with multimedia data. All these concepts are addressed in Wiki-Learnia as the following paragraphs will show.

First of all, Wiki-Learnia delivers a social learning environment. Certain communication mechanisms such as 
chats, forums, and personal messages facilitate discussions and cooperation in the community. Like in other social networks, each user has an own profile site with a bulletin board, where other members or he himself can publish states, thoughts, or share web links.

Wiki-Learnia is not only a social network on its own, but also integrates existing ones like Facebook, Twitter, and Youtube, similar to the approaches [13] and [14]. By means of a single sign-on mechanism combined with a cross-network connection, a communication between Wiki-Learnia users and members of other social networks is enabled. Actual status information of friends like bulletin board messages, feeds, or comments are automatically imported from the connected social networks.

As the name suggests, the basis of Wiki-Learnia is a wiki software, in particular the MediaWiki. This enables a native collaboration between users by creating or editing articles together directly online in the web browser. An integrated versioning tool and a discussion platform enhance this feature. A lot of additional functionalities were added to facilitate this work. To reduce the initial threshold of common MediaWiki systems such like Wikipedia, a WYSIWYG editor is used instead of learning the wiki syntax. This editor enables an easy import of user-generated offline content like images, PDFs, Word documents, and the XML4TIO format which is necessary to integrate content from the TIO project.

Because the TIO content is proposed for certification in a further education procedure, it's essential that this material cannot be modified by the community. It's readonly, but can be commented and annotated. The first one is achieved by sticky notes users can pin on any text position. This information can be viewed by every user of the community and provides a feedback for the author(s). To achieve the latter one, there's an easy annotation tool integrated into Wiki-Learnia. Each user can mark passages and add comments only they can see in their virtual desktop environment. This simulates the classical work of a learner with his printed manuscripts where he can add any annotations.

Another important offline generated learning material is the eLecture which is an effective mapping of real-world face-to-face lectures. It's a video recording of a person talking about a certain topic with corresponding synchronized presentation slides and simple navigation features. On the one hand, this content can be created with thirdparty software like LECTURNITY [15] and then can be easily included as flash format into any Wiki-Learnia article. Users can watch the video, and jump at anytime to any slide by selecting from a list or searching using keywords. On the other hand, a special Android tool for mobile presentation creation is developed by the University of Rostock. By means of a smartphone or a tablet PC with an integrated webcam and a microphone the user can create easily presentations. It's possible to import existing PPT, PDF and other image files, or create new slides. With the editor slides can be modified by adding texts and figures on a special layer, so the original files aren't affected. After the slides are created, the user can make a recording where he's speaking in front of the camera and switch manually the slides. Everything is saved in a synchronized manner and can be exported as video or flash format, which can directly be integrated into WikiLearnia.

\section{Web/eLearning 3.0 Features}

As Web 3.0 has not yet been clearly defined, there're only some predictions of the future of eLearning 3.0. [16] and [17] assume a higher importance of mLearning. The "concept of 'anytime, anywhere and anybody' will be complemented by 'anyhow"” which means that all learning content will be available on all types of devices. Furthermore, both contributions as well as [11] believe that methods from semantic web and A.I. will be adopted into Web 3.0. [11] speaks of a paradigm shift from a topdown to a bottom-up approach in science. The former one contains the three steps: first define a hypothesis, then collect necessary data, and finally analyse it to evaluate the hypothesis. In the past the second step was very expensive related to time and money. Nowadays by means of parallel computing, high performance computing, as well as cloud computing this procedure has become much cheaper. For this reason, now we have a data-driven science: first gather data, then analyze it by means of A.I. mechanisms (data-mining), and finally discover a hypothesis [11].

This "big data" issue is already present in the eLearning context. Because of Web 2.0 technologies like blogs, wikis, tweets etc. there's a sufficient mass of learning material in the web. [11] advises the use of A.I. technologies in eLearning 3.0 LMSs such as semantic filtering and recommendation systems.

The use of those mechanisms is essential for WikiLearnia in the functionality as an eLearning-Hub. This means Wiki-Learnia is a central point for learning, connecting several learning interfaces and repositories (Figure 5).

Content from universities, industry, further education companies, additional web interfaces like Wikipedia, GoogleBooks and social networks (as described above), as well as from every person in the world are combined in Wiki-Learnia by means of the community (crowdsourcing) and developed semantic tools.

In Wiki-Learnia every user can select an actual learning goal which is similar to the idea of sharing a status in other social networks. Based on this information in addition to the learning history, including last read articles, relevant facts from connected interfaces like social networks can be filtered by means of a keyword comparison.

The same information is used to recommend individual learning content to the users, which is a central functionality of Wiki-Learnia as a further education solution for livelong learning. The basis is a categorizing connected with a tagging of each article, which are both supported by the system doing automatically semantic analysis. The defined learning goal is also a category which is the first filtering criteria for a suitable recommendation. Furthermore the elimination of already read articles as well as the consideration of learning paths refines the selection. The latter one is related to the manually or automatically creation of learning paths based on the "WikiTrails" concept [18]. On this way, users can also search for complete learning paths instead of pure articles in WikiLearnia. If the user's last read articles are included in a selected learning path all other articles of this one are not recommended. Finally, the remaining article list is prioritized on the basis of user rankings. 


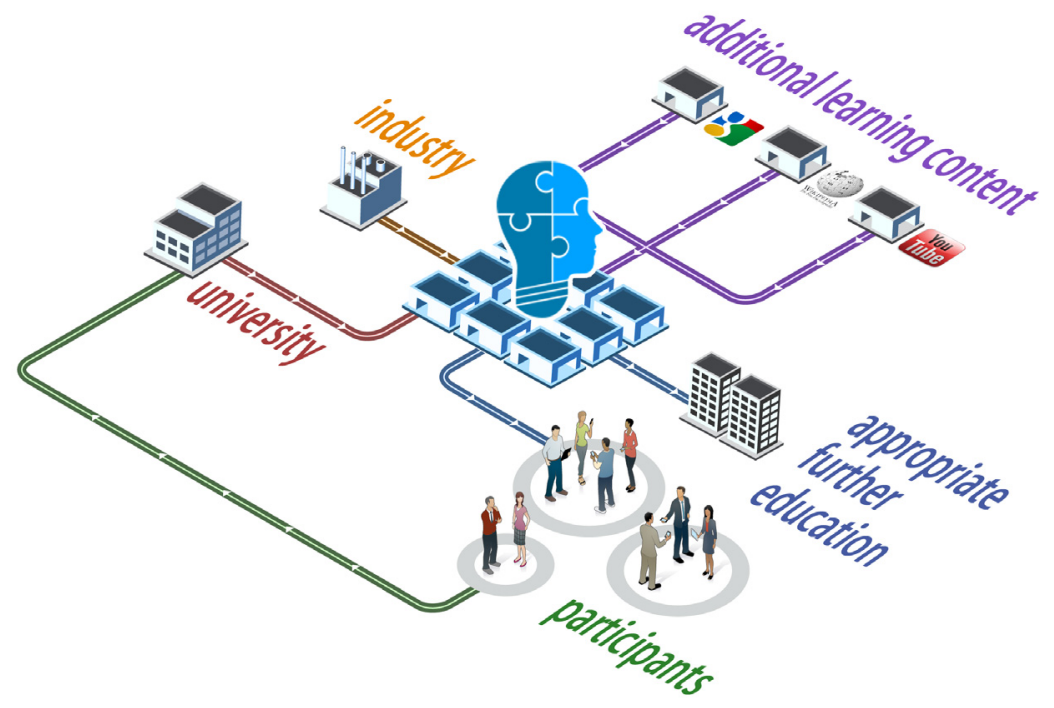

Figure 5. Wiki-Learnia as an eLearning-Hub

In addition to this recommendation system there're other ones especially for authors. Based on the history of written articles of an author, he will automatically be pleased for writing some other content- and skill-related, not yet existing articles. Another recommendation system helps them to categorize their written articles. Based on a text analysis, the system automatically recommends fitting categories, which the user can just accept or choose from a given list. Additionally the same mechanism is used to generate a list of further literature for any article.

Like the ILIAS concept described in II, also all WikiLearnia content is offered for mobile devices by means of HTML5 and CSS. As a special feature, the user has the opportunity to create a collection of selected content and in the end to download it as PDF or even as native mobile device application for Android, iOS, Blackberry or WindowsPhone. Consequently, it will be possible to distribute certain learning material via the different mobile stores.

\section{CONCLUSION AND OUTLOOK}

\section{A. Conclusion}

With the development of two online study programs for B.Sc. and M.Sc. in computer engineering, a consortium of five North German universities create a solution to the skills shortage problem in the IT sector.

Referred to the blended learning strategy, the main part of the program, apart from a few class lectures, is offered online. Using the well-known open source LMS ILIAS which is optimized for classical learning mechanisms, the users only need an internet browser. All content will be dressed according to the technical specifications of each system. This is possible because of using a single source publishing principle. Authors can create learning contents in their familiar word processing environments. Then this material is converted into an XML format which is the basis for different output transformations.

In order to support a better learning experience, the whole curriculum is enriched with a variety of multimedia data. In addition to simple texts, the individual learning objects contain pictures, animations, audio and video material. Embedded self-test exercises, an intuitive system to communicate with other students and tutors in a social network environment, and the opportunity to make own notes, to use blogs with a feedback system, to create ePortfolios with different views and accessibilities, complete the overall solution.

For the Master's program of TIO, which is designed as an extra-occupational further education concept, another completely novel platform called "Wiki-Learnia" is used. In contrast to ILIAS, which is an eLearning 2.0 portal, Wiki-Learnia also includes Web 3.0 features. By including certain learning interfaces and repositories such as existing social networks (Facebook, Twitter, Youtube etc.), Wikipedia, and GoogleBooks, it's a first implementation of an eLearning-Hub. This deals as a central station for collecting, creating and distributing learning content. For an effective use of this information mass, various recommendation mechanisms are included into WikiLearnia to support the learners.

Another special feature of this eLearning 3.0 portal is the combination of formal and informal learning within a social network environment. Based on a MediaWiki every user can add or edit content, and use all articles for informal learning processes. But there're also read-only materials from universities, schools, and other further education institutions for certification procedures, which can only be commented and annotated by the community.

\section{B. Outlook}

Both study programs of TIO will start in winter 2013 in pilot operation phase. Wiki-Learnia as a new eLearning portal will release earlier in the summer and the master's program will follow as first further education material. At the beginning students can already enroll, but not all features are yet included in the system. First it will be used as an experimental platform. Here, users can give a lot of feedback about pros and cons of the portal. New features will be implemented in parallel, and will be tested, as well as validated by the users.

Since Wiki-Learnia as an eLearning 3.0 portal also implements the most important features of ILIAS, in future 
even the Bachelor's program should be integrated into Wiki-Learnia. Better social network properties, as well as Web 3.0 features like recommendation of further literature will improve the learning experience.

\section{ACKNOWLEDGMENT}

We thank the TIO project team which was realized by the political initiative "Virtuelle Hochschullandschaft Norddeutschland" (VHN; English: Virtual University Landscape North Germany). This consortium includes:

- University of Hamburg, Department TIS, Prof. Dr.Ing. D. P. F. Möller (coordination);

- University of Rostock, Research Group of Computer Architecture, Prof. Dr.-Ing. habil. D. Tavangarian;

- University of Lübeck, Faculty of Technical Sciences, Prof. Dr. rer. nat. S. Fischer;

- Clausthal University of Technology, Institute of Computer Science, Prof. Dr. H. Richter;

- Hamburg University of Technology, Department TI6, Prof. Dr. rer. nat. F. Mayer-Lindenberg.

Special thanks are due to the TIO and the Wiki-Learnia working team which implements the whole TIO and WikiLearnia system architecture.

\section{REFERENCES}

[1] Die Welt: Deutschland beklagt 210.000 fehlende Fachkräfte. http://www.welt.de/wirtschaft/article106368664/Deutschlandbeklagt-210-000-fehlende-Fachkraefte.html, Axel Springer AG, 2012.

[2] Kempf, D.: Der Arbeitsmarkt für IT-Fachkräfte. BITKOM, 2012.

[3] Meincke, F., Tavangarian, D.: Computer Engineering Online Best Practice in Long Distance Approaches for Lifelong Learning. 14th International Conference of Interactive Collaborative Learning (ICL), 2011. http://dx.doi.org/10.1109/ICL.2011.6059567

[4] Leszczensky, M., Gehrke, B., Helmrich , R.: Bildung und Qualifikation als Grundlage der technologischen Leistungsfähigkeit Deutschlands, HIS: Forum Hochschule - Ausgabe 13, 2011.

[5] Multidimensional LearningObjects and Modular Lectures Markup Language $<\mathrm{ML}^{3}>$. http://www.ml-3.org/.

[6] Lucke, U., Meincke, F., Tavangarian, D.: Business as Usual: Guidelines to Using Common Word Processors for XML based Teachware. World Conference on Educational Multimedia (EDMEDIA), 2011.

[7] ILIAS. Open Source e-Learning. http://www.ilias.de.
[8] Mason, R., Pegler, C. \& Weller, M. (2004): E-portfolios: an assessment tool for online courses.. British Journal of Educational Technology Vol 35, No 6, S. 717-727. http://dx.doi.org/10.1111/ j.1467-8535.2004.00429.x

[9] Djamshid Tavangarian und Ulrike Lucke. Pervasive University A Technical Perspective. it - information technology, 2009.

[10] Statistisches Bundesamt DESTATIS: Bildung und Kultur Nichtmonetäre hochschulstatistische Kennzahlen 1980-2010. 2012.

[11] N. Rubens, D. Kaplan, and T. Okamoto. E-Learning 3.0: anyone, anywhere, anytime, and AI. International Workshop on Social and Personal Computing for Web- Supported Learning Communities, 2011

[12] W. Richardson. The educator's guide to the read/write web. Educational Leadership, 63(4):24, 2005.

[13] friendica, http://friendica.com/, November 2012.

[14] Social Igniter, https://social-igniter.com/, November 2012.

[15] LECTURNITY, http://www.lecturnity.de, January 2013.

[16] H. Rego, T. Moreira, E. Morales, and F.J. Garcia. Metadata and Knowledge Management driven Web-based Learning Information System towards Web/e-Learning 3.0. International Journal of Emerging Technologies in Learning (iJET), June 2010.

[17] S. Wheeler. e-Learning 3.0: Learning through the eXtended Smart Web. In National IT Training Conference, number March, 2011.

[18] S. Reinhold. WikiTrails: Augmenting Wiki Structure for collaborative, interdisciplinary Learning. In Proceedings of the 2006 international symposium on Wikis (WikiSym '06), 2006.

\section{AUTHORS}

I. Waßmann is research assistant and at the Research Group of Computer Architecture at University of Rostock, Faculty of Computer Science and Electrical Engineering, 18059 Rostock, Germany (e-mail: ingolf.wassmann@unirostock.de). He focuses its research on novel eLearning platforms based on social environments combined with Web 3.0 features and cloud computing technologies.

D. Tavangarian is the head of the Research Group of Computer Architecture at University of Rostock, Faculty of Computer Science and Electrical Engineering, 18059 Rostock, Germany (e-mail: djamshid.tavangarian@unirostock.de). He focuses its research on computer architecture topics relating to energy-efficient data centers, cloud security, and mobile internet architectures for eLearning.

Received 15 January 2013. Published as submitted by the authors 11 February 2013. 